PRINT ISSN: 2249-6637

ONLINE ISSN: 2321-5771

\title{
Contents
}

\section{International Journal of Social Sciences}

Vol. 9, No. 4, December 2020

Integration of Internet Memes in Teaching Social Studies and its Relation to the Development of

Critical Thinking Skills: A Literature Review

Keno Ivan O. Matias

A Works Council's Response to Decent Work Deficits Facing Agricultural Employees in Zimbabwe

Moment Bhebhe and Prince Takaindisa

Participatory Action Research Saved Bullocks of Village Kanadwadi, Maharashtra from Potential Threat of Horn Cancer and Skin Allergy

Bharadwaj S., Naik K.P., Chittora R.K. and Upreti N.C.

Changing fashion finding Changing Cities: Addressing the Gender Barriers

Anuj Behal

Indigenous Culture and Medicine

S. Anandakumar and G. Ramakrishnan

$18^{\text {th }}$ Century Village Craftsmen: A Socio-Economic Study of Marvar

Neha Singh

Socio-Demographic Changes Among the Parsis in Delhi, India

Stuti Singh and Roumi Deb

Women Empowerment through Self-Help Groups (SHGs) in Three Dimensions: An Empirical Study of Rural Andhra Pradesh

K. Harika, K. Raviteja and V. Nagaraju 
Determinants of Life Satisfaction for Rural North Indians: Estimation Using Generalised Ordinal Logistic Regression

Suraj Sharma

Hirakud Dam Oustees and Procrastination of Justice in India

Ashok Dansana

Growth Status of Unorganised Food Processing Enterprises in India

Akash Dandapat, Soumita Dasgupta and Pinaki Das

Employees Assistance Programme; Social Work at Workplace : An Evidence Based Review

Kuntak Ghosh

A Study of Feudal Coalition and Control System in Tokugawa Japan

Ajoy Kumar Das

Urban Ecosystem Changes Around Natural Drains: Case of Becharji Nala of Vishwamitri River in Vadodara City

Munjal Mehta and Dimple Behal 